\title{
Ñetonqataiqén, una canción «en desplazamiento»
}

\author{
Prácticas musicales y visibilización mocoví \\ en la provincia de Santa Fe, reflexiones \\ en torno a un caso de estudio
}

\author{
Valentín Mansilla \\ [Universidad Nacional de Córdoba]
}

Resumen La presencia de prácticas musicales durante la coyuntura política actual de los pueblos originarios en Argentina (atravesada por procesos de reagrupamiento y lucha por su visibilización) viene siendo escasamente abordada por los estudios etnomusicológicos. En el presente trabajo me propongo reflexionar sobre la escena del pueblo mocoví en la provincia de Santa Fe a partir de un caso concreto: el "trayecto" de una canción creada por uno de sus dirigentes (Alfredo Salteño) para ser interpretada durante los encuentros comunales que luego fue versionada por un músico profesional (Luis Sartor) para ser enseñada en escuelas rurales.

Por medio del análisis de cuatro versiones (tres pertenecientes a Salteño y una a Sartor) pretendo dar cuenta de las transformaciones efectuadas y de algunos de sus usos con el objetivo de ensayar posibles respuestas a los interrogantes que subyacen a este trabajo, a saber: ¿de qué modos opera esta canción en el proceso de visibilización mocoví? ¿Qué acciones habilita su nueva versión? ¿Qué aspectos de este movimiento social y de su dimensión estética nos deja entrever el estudio de su «vida cambiante»?

Palabras clave: Mocoví - Santa Fe · población indígena $\cdot$ música tradicional
Summary Ethomusicological studies focused on the musical practices present in the current situation of indigenous people in Argentina (marked by on-going proceses and struggles for their visibilization) are thin on the academic ground. In this paper I think about the mocovi's situation in Santa Fe province from a particular case of study: the "travel" of a song which was created by one of their leader (Alfredo Salteño) in order to be performed in their community meetings, and then was arranged by a professional musician (Luis Sartor) to be teached in rural schools.

Through the analysis of four versions of the same song (three performed by Salteño and one by Sartor) I pretend elucidate their uses and transformations in order to draw up some answers to the underlying questions of this work: how impacts this song in mocovi's visibility processes? What kind of actions are afforded by the new version? What features of this social movement and their aesthetic dimensions we can observe studying their "changing life»?

Keywords: Mocoví - Santa Fe ·

Indigenous population · Traditional music 


\section{$1 \cdot$ Introducción}

Hace aproximadamente cuatro décadas que, en Argentina, los pueblos originarios se encuentran inmersos en procesos de reagrupamiento y de lucha por su visibilización. ${ }^{1}$ Dentro de este contexto es posible reconocer a las prácticas musicales como parte de las acciones culturales que los pueblos vienen efectuando para propulsar tales movimientos sociales. A pesar de su presencia, son aún escasos los trabajos etnomusicológicos que se han ocupado de reflexionar sobre dicha escena. Entre ellos, podemos mencionar abordajes locales y provinciales en relación con los pueblos qom y colla realizados por Silvia Citro y Soledad Torres Agüero (2015, 2017), y Rosario Haddad (2018, 2020), así también, el análisis efectuado por la etnomusicóloga Irma Ruíz (2003), quien se encargó de reflexionar sobre la escena a nivel nacional a través de un estudio comparativo con el movimiento «pan-indígena» norteamericano.

Teniendo en consideración tales trabajos podemos asumir que se trata de un terreno complejo, por un lado, debido a la interacción entre grupos originarios y no-originarios, ${ }^{2}$ y por otro, a causa de los intereses y acciones divergentes que se presentan tanto entre las comunidades involucradas como al interior de las mismas. A pesar de tal complejidad considero que procesos de este tipo podrían ofrecer una oportunidad interesante para explorar qué sucede con las expresiones musicales al interior de las luchas, cuáles son las privilegiadas y por qué, cómo son

1 Tales movimientos sociales, también denominados por la academia como procesos de "etnogénesis" o de "reemergencia étnica", vienen sucediéndose con frecuencia durante el siglo XX en distintas latitudes del mundo. Respecto al caso argentino, desde el retorno a la democracia se han presentado numerosas «reemergencias" de pueblos originarios que, según las narrativas hegemónicas (forjadas principalmente por el Estado y la academia), se habían extinguido en procesos de aculturación e hipodescendencia. Tales procesos se vieron favorecidos por conquistas constitucionales como la Ley Nacional 23302 del año 1985 sobre Política Indígena y apoyo a las Comunidades Aborígenes, y el artículo 75 inciso 17 que reconoce, entre otras cosas, la preexistencia étnica de los pueblos originarios. Para una indagación más profunda del término «etnogénesis" puede consultarse Bartolomé (2006:193-220). En dicho trabajo el autor reconoce y discute cuatro usos principales que ha tenido, y suele tener, el concepto en la producción antropológica. En relación con el término "visibilización", creo necesario enunciar que, si bien considero que puede resultar problemático, lo utilizaré en este escrito al ser el empleado por mis informantes para referirse al proceso de lucha en el cual se reconocen inmersos.

2 Por ejemplo, instituciones eclesiásticas, ONGs, instituciones académicas, especialistas en derechos humanos, entre otros (Ruíz 2003:25-26). 
instrumentalizadas por diferentes grupos y cómo impactan en los procesos de visibilización.

Este grupo de interrogantes ha servido de estímulo para abordar el presente trabajo. Sin embargo, se trata de preguntas abarcadoras, notablemente generales, ante las cuales no procuré ensayar respuestas precisas. Más bien, debido a mi conocimiento incipiente sobre el tema y a la situación sanitaria actual (que solo me permitió realizar una etnografía desde la (in)comodidad de mi hogar), ${ }^{3}$ opté por explorar un caso particular: el «trayecto» de una canción («Netetonqataiqén») creada por un dirigente mocoví (Alfredo Salteño) que fue versionada por un músico profesional (Luis Sartor). Ambos actores han estado implicados en los procesos de visibilización del pueblo mocoví en la provincia de Santa Fe (Argentina).

De este modo, con el foco ajustado en el caso mencionado, fue posible delinear un segundo grupo de interrogantes, más específicos, sobre los cuales sí me propuse explorar detenidamente, a saber: ¿de qué modos opera esta canción en el proceso de visibilización mocoví? ¿qué acciones habilita su nueva versión? ¿qué aspectos de este movimiento social y de su dimensión estética nos deja entrever el estudio de su «vida cambiante»?4

Para discurrir sobre ellas estructuro el trabajo en cinco secciones. La primera se ocupa de reponer brevemente el contexto de la canción y

3 Debido al contexto epidemiológico parte del trabajo consistió en una suerte de ethnography at home que implicó, por un lado, entrevistas telefónicas con los protagonistas de este escrito (Alfredo Salteño y Luis Sartor), con miembros de la comunidad mocoví Aim Mokoilek de Colonia Dolores (Dora Salteño, Salvador Salteño y Cesar Coria), con maestros bilingües interculturales (Máximo Santos y Éctor Catorí) y con otros actores allegados a las comunidades mocoví que colaboran con el proceso de visibilización, entre ellos, la actual secretaria adjunta de la Junta Directiva Provincial de la Asociación del Magisterio de Santa Fe (Patricia Hernández) y el músico Miguel Ángel Bochini. Por otra parte, también implicó el relevamiento de datos en diversas plataformas digitales (Facebook, Youtube, Spotify, periódicos digitales, etc). Hay voces y datos que lamentablemente no pude incluir. Los registros sonoros que analizo no fueron tomados por mí dado que datan de varios años antes a comenzar mis estudios sobre este tópico. Sin embargo, resultaron pertinentes a los fines de desarrollar el enfoque pensado para este escrito.

4 La elección de esta perspectiva, de indagar en el devenir de una canción, estuvo inspirada en la categoría de "trashumancia" desarrollada en Gilbert y Liut (2019), como también en el énfasis que otorga Pablo Seman, en el prólogo de dicha publicación, a la relevancia de explorar su «vida cambiante» a los fines de dilucidar relaciones entre las músicas y las sociedades (relación que considero central en escenarios como el descripto donde las prácticas musicales se encuentran imbricadas en los procesos políticos de los pueblos originarios). 
a los actores protagonistas. Las dos secciones siguientes presentan una descripción y un análisis de cuatro versiones registradas (tres correspondientes a Salteño y una a Sartor). Seguidamente, enuncio una serie de «desplazamientos» que observo en «Ñetonqataiqén» luego de la intervención de Sartor. Finalmente, planteo algunas reflexiones acerca de cómo considero que dichas modificaciones inciden en el proceso de visibilización mocoví.

\section{$2 \cdot$ «NETETONQATAIQÉN»}

La canción que protagoniza este escrito tuvo su origen al interior de la comunidad mocoví ${ }^{5}$ Aim Mokoilek en un contexto de recuperación y reelaboración de prácticas musicales y coreográficas del pasado. Aim mokoilek, ${ }^{6}$ radicada en la localidad de Colonia Dolores, cuenta con una destacada trayectoria en la recuperación de su patrimonio material e inmaterial, la creación de nuevas expresiones culturales y la comunicación con instituciones externas (estatales, académicas y privadas) con lo cual ha ido tornándose un caso de referencia para las luchas por la visibilización del pueblo mocoví en la provincia de Santa Fe. ${ }^{7}$

Se trata de un pueblo que no ha estado exento de un pasado fuertemente atravesado por las persecuciones emprendidas tanto por el Estado como por los colonos de la región durante la conformación del Estado nacional argentino. Además de numerosas muertes, tales persecuciones indujeron la dispersión geográfica de las familias mocoví y la imple-

\footnotetext{
5 "Mocovín es el etnónimo utilizado comúnmente en castellano y el cual adoptaré en este trabajo al ser el mayormente empleado por las personas que entrevisté. Para referirse a sí mismos en lengua originaria el etnónimo utilizado es "moqoit».

6 En español "soy mocoví».

7 A partir del año 2002 la comunidad comenzó a trabajar sostenidamente para obtener el reconocimiento estatal (concedido en el año 2008). Algunas de las acciones emprendidas desde aquel proceso fueron: la creación de una bandera del pueblo mocoví (la cual ha sido adoptada por otras comunidades de la provincia), la creación de un himno (recitado junto a un toque de tambor en cada encuentro comunal e intercomunal), la inauguración de un museo comunal y la puesta en funcionamiento de una radio FM local. Para tener una idea más cabal sobre las diferentes instancias que ha ido atravesando la población mocoví de Colonia Dolores hasta conseguir la personería jurídica puede consultarse Dalla-Corte Caballero (2012).
} 
mentación, por parte de estas, de "tácticas» de invisibilización (Citro, 2006b) que decantaron en el abandono de algunas prácticas culturales que pusieran en evidencia su proveniencia étnica, entre ellas la transmisión del idioma. Según el relato de Dora Salteño, integrante y exdirigente de Colonia Dolores, la comunidad viene adentrándose desde la década de 1990 en la recuperación de prácticas y saberes "ancestrales» a través de la consulta a sus ancianos y ancianas, ${ }^{8}$ quienes habían llegado a escuchar y observar de pequeños a las generaciones anteriores y aún conservaban conocimiento del idioma.

Tal ejercicio de la memoria permitió, por ejemplo, reponer dos rituales en sus encuentros comunales e intercomunales: el «saludo a los cuatro vientos» y el «encendido del fuego sagrado». Sin embargo, las prácticas musicales y coreográficas presentaron recuperaciones fragmentarias. ${ }^{9}$ Según el relato de D. Salteño, en sus encuentros empezaron a implementar una coreografía circular tomando «el paso del baile de la vizcacha, pero sin música, sin nada, porque no había nada para hacerlo». ${ }^{10}$ Ante esta falta, los miembros de Aim Mokoilek solicitaron a uno de sus integrantes ancianos, Alfredo Salteño, la creación de una canción en idioma mocoví para poder complementar la coreografía. De este modo, A. Salteño creó «Ñetonqataiqén» ${ }^{11}$ y fue incorporada a los encuentros comunales e intercomunales para ser interpretada luego de los dos rituales mencionados.

8 Este proceso también contó con la participación de actores externos a la comunidad. Entre ellos es posible nombrar a Bertha Gallardo, directora de la Escuela № 430 de Colonia Dolores durante la década de 1990, quien se preocupó por la recuperación de prácticas coreográficas; la antropóloga Silvia Citro, quien se enfocó en prácticas musicales y coreográficas, ver Citro (2006a); y la arqueóloga Paula Del Río, quien indagó en el patrimonio material e inmaterial a través de un trabajo sostenido en instancias de taller y tareas de excavación, ver Del Río (2013).

9 A excepción de una práctica tradicional que ha pervivido el paso del tiempo y se continúa practicando durante uno de los festejos principales de la comunidad, la fiesta del 30 de agosto. Ver nota 19.

$10 \mathrm{El}$ "baile de la vizcacha" integra los denominados "bailes paisanos". Se trata de prácticas musicales y coreográficas tradicionales del pueblo mocoví de la región santafesina que dejaron de realizarse a mediados del siglo XX. La adjetivación "paisanos" es implementada como sinónimo de "mocovín y es utilizada para diferenciarse de los "criollos" (Citro 2006a, 12; comunicaciones personales con Alfredo y Dora Salteño).

11 Traducida por A. Salteño como «alegrémonos». Según el maestro bilingüe Máximo Santos, la partícula "-quén" puede traducirse como "ahora y siempre" (alegrémonos ahora y siempre). 
Años después, en enero de 20I4, algunos integrantes de la comunidad conocen al músico Luis Sartor, oriundo de la ciudad de San Javier, ${ }^{12}$ quien estaba comenzado a interesarse por la cultura mocoví y su difusión. Luego de algunos encuentros, fueron invitados por el músico a San Javier para continuar con las conversaciones. En aquella oportunidad se dirigieron a un estudio de grabación y realizaron una serie de registros sonoros en los cuales se expresaron sobre diferentes tópicos (bandera, himno, bastón del cacique, cosmología, leyendas y prácticas musicales). En este contexto, A. Salteño, que estaba presente, interpretó «Netonqataiqén». ${ }^{13}$ Luego de dos años, Sartor decidió incluir la canción de Salteño en el repertorio musical de un proyecto que se encontraba próximo a iniciar, La Flauta de Paikí, el cual consistió en la creación de agrupaciones vocal-instrumentales en escuelas rurales cercanas a la ciudad de San Javier. ${ }^{14}$

En este "trayecto», de Salteño a Sartor, la canción no quedó exenta de transformaciones. Para dar cuenta de ello destino las dos secciones siguientes a describir y analizar, por un lado, tres versiones interpretadas por Salteño antes de la intervención de Sartor, por otro lado, la versión del músico para ser enseñada en las escuelas.

\section{$3 \cdot$ LAS Versiones de SALTEÑo}

Las versiones de «Ñetonqataiqén» interpretadas por Salteño a las cuales tuve acceso fueron tres y han sido registradas en años consecutivos (2013, 2014 y 20I5). La primera de ellas fue realizada durante el 2 do Encuentro

12 Ciudad cercana, por cincuenta kilómetros, a Colonia Dolores. Se trata de una localidad atravesada históricamente por la presencia del pueblo mocoví y en la cual también se han iniciado procesos de comunalización. La ciudad de San Javier fue fundada en 1743 como una reducción jesuítica habitada por parcialidades del pueblo mocoví y fue allí donde sucedió, en 1904, la "última rebelión" mocoví, la cual tuvo como resultado numerosas bajas para el pueblo originario y el incremento de las persecuciones armadas.

13 La reunión quedó registrada en trece audios que luego fueron compilados por Sartor en un disco compacto y distribuidos a la comunidad Aím Mokoilek.

14 Las escuelas que integraron el proyecto fueron: № 6099 (San Javier), № 6085 (Colonia Francesa), № 444 (Colonia Francesa) y № 1311 (Colonia Criolla). 
de Familias Aborigenes de la Costa, ${ }^{15}$ la segunda corresponde a las grabaciones efectuadas al interior de la reunión mencionada en el apartado anterior (entre los miembros de la comunidad Aim Mokoilek de Colonia Dolores y Sartor) en la ciudad de San Javier; y la tercera, lamentablemente incompleta, fue registrada durante la celebración del dalagaic ñaga moqoit (año nuevo mocoví) ${ }^{16}$ en la localidad de Colonia Dolores.

En todas las versiones, el canto fue realizado por Alfredo Salteño. Sin embargo, los instrumentos variaron en cada ocasión: en la primera, fue ejecutado un pinkuyo ${ }^{17}$ (por Salteño), un tambor y un «violín» monocorde de lata ${ }^{18}$ (cada uno por un varón adulto). En la segunda, además del pinkuyo, Salteño ejecutó una guitarra (realizando rasguido de cha-

15 Organizado en la localidad santafesina de Helvecia. Según el relato de Dora Salteño (pariente de Alfredo) fue la primera vez que se interpretó "Ñetonqataiqén" fuera de Colonia Dolores.

16 Los grafemas que utilicé para denominar al evento responden a los criterios de escritura empleados en las comunidades mocoví santafesinas. En la provincia de Chaco, tales criterios se diferencian y se corresponden principalmente con los sistematizados por Alfred Buckwalter en su Vocabulario Mocoví de 1995, con lo cual podría encontrarse como: dalaxaic ñaaxa moqoit. Agradezco a Máximo Santos (profesor bilingüe intercultural de la comunidad Pedro José, ciudad de Tostado) por los datos ofrecidos. Dicha celebración se realiza actualmente el 30 de agosto y se trata de un sincretismo entre dos festejos. Por un lado, la renovación del ciclo natural, y por otro, la devoción a Santa Rosa de Lima. Según el relato de Dora Salteño, la primera de ellas no tenía, antiguamente, una fecha exacta sino que era efectuada luego de las "señales" brindadas por la naturaleza (comunicación personal, julio de 2020). La segunda fue adoptada durante el período de tutela misional franciscana (iniciado en las últimas décadas del siglo XIX). La implementación de festividades católicas, con fechas precisas, cercanas temporalmente a eventos correspondientes a las culturas originarias fue una estrategia frecuentemente ejecutada por misioneros de diversas órdenes eclesiásticas en el continente americano en el marco de sus prácticas de evangelización. Actualmente, a sabiendas de esta particularidad, la comunidad de Colonia Dolores decide mantener ambas celebraciones con rituales afines a cada una de ellas. Es un tópico para desarrollar extendidamente y que no abordaré aquí. Para indagar en esta celebración recomiendo consultar Citro (2006a).

17 En las entrevistas realizadas me han referido a dicho instrumento de tres maneras diferentes (flauta, quena y pinkuyo) siendo "flauta" la más utilizada, como si se tratara de un término genérico.

18 Se trata de un cordófono, de cuerda frotada, construido por el artesano mocoví Néstor Lanche. Si bien este último lo denomina "violín mocovín o "vike moqoi» presenta claras similitudes con el n'viké qom. Para una descripción detallada de su construcción puede consultarse Ruíz (1985:71-73). A diferencia del n'viké qom el arco se construye con una costilla de potro (aunque pueden utilizarse otros materiales en caso de no contar con este). Si bien el n'viké ha sido un instrumento ampliamente registrado en los grupos qom y pilagá, no lo es para el caso mocoví. Según lo que he podido observar, la utilización del vike moqoi en los eventos realizados por las comunidades mocoví en la provincia de Santa Fe no es colectiva. Se trata, más bien, de un uso particular por parte del artesano Néstor Lanche. Según su relato, aprendió a fabricar el instrumento gracias a la instrucción de un artesano mocoví de la provincia de Chaco en la década de 1990 (comunicación personal, febrero de 2021). Puede consultarse el siguiente link para observar su ejecución: https://www. youtube.com $/$ watch? $v=\mathrm{B} 1 \mathrm{kzsaCz} Y \mathrm{Ys}$ 
mamé) y otro intérprete (varón adulto) el tambor. Finalmente, en la tercera versión Salteño solo utilizó su voz y algunos bailarines ejecutaron idiófonos: un sonajero de calabaza (por mujer adulta) y dos chauchas (por mujer adulta y niño):

Tabla I: Orgánico instrumental de las tres versiones

\begin{tabular}{|c|c|c|c|}
\hline Versiones & 2013 & 2014 & 2015 \\
\hline & Voz (masculina, adulta) & Voz (masculina, adulta) & Voz (masculina, adulta) \\
\hline & Pinkuyo & Pinkuyo & \\
\hline & \multicolumn{3}{|l|}{ Violín monocorde } \\
\hline & Tambor & Tambor & \\
\hline & & Guitarra & \\
\hline & & & Sonajeros de calabaza / Chauchas \\
\hline
\end{tabular}

Pese a tales diferencias, el pinkuyo y el tambor fueron utilizados conjuntamente en dos de las tres versiones. La elección de esta configuración instrumental (un aerófono junto a un membranófono) no pareciera ser casual. Se trata de instrumentos particularmente representativos para la comunidad de Colonia Dolores y ha sido frecuentemente registrada en grupos mocoví de la región a lo largo del tiempo. ${ }^{19}$

19 El uso de aerófonos y membranófonos en conjunto con el canto para ciertos eventos sociales fue una práctica frecuentemente observada por los misioneros jesuitas durante el siglo XVIII dentro de la reducción mocoví de San Javier (Paucke 2010:207, 317 y 596). Por otra parte, la Encuesta Nacional de Folklore de 1921 también menciona el uso ritual de un aerófono y un membranófono durante las celebraciones de Santa Rosa, San Javier, San Ramón, San Antonio, San Juan y Navidad (Encuesta Nacional de Folklore de 1921, Leg. Santa Fe, Carpeta 24, f. 49). Para el caso de Colonia Dolores, Dora Salteño, Salvador Salteño y Cesar Coria reconocen el uso de ambos instrumentos como una práctica "ancestral" correspondiente a la fiesta del 30 de agosto. Para dicha celebración estos son ejecutados con toques particulares cuyo aprendizaje se realiza mediante la transmisión oral intergeneracional (comunicaciones personales entre julio y agosto de 2020). Otra prueba de la relevancia de dicha configuración instrumental es la mención a ambos instrumentos en los primeros versos del Himno Mocoví: «El sonar del tambor me hace vibrar de emoción, es la sangre mocoví que impulsa mi corazón. Acompaña dulce flauta al tambor, juntos otra vez. Gritando a los cuatro vientos que el mocoví está de pie». La autoría del himno corresponde a Cesar Coria, integrante de la comunidad de Colonia Dolores, y es recitado junto al toque del tambor en diversos tipos de eventos comunales e intercomunales. 
En cuanto a la dimensión formal, Salteño dividió a «Ñetonqataiqén» en dos secciones en todas las versiones. Los registros de 2013 y 2014 presentan una sección instrumental seguida de otra vocal-instrumental, mientras que, en el registro de 2015, ambas son vocal-instrumentales (la primera con canto melismático sin letra y la segunda con canto silábico). Las duraciones de cada una de ellas presentaron notables diferencias en los tres registros:

Tabla 2: Duraciones por sección

\begin{tabular}{|l|ll|lllll}
\hline Versiones & 2013 & & \multicolumn{2}{c}{$\mathbf{2 0 1 4}$} & & 2015 \\
\hline Secciones & Instr. & Voc-instr. & Instr. & Voc-instr. & Voc-instr. & Voc-instr. \\
\hline Duración & $50^{\prime \prime}$ & 3' $30^{\prime \prime}$ & $38 "$ & $50^{\prime \prime}$ & (registro incompleto) & $28 "$
\end{tabular}

Las melodías de la flauta y el canto también fueron divergentes en cada interpretación. La extensión de las frases, el repertorio de alturas y el comportamiento rítmico no se presentaron igual en ninguna de las versiones. Esto se debió al predominio de la improvisación. ${ }^{20} \mathrm{~A}$ modo de ejemplo, podemos observar el perfil melódico de las secciones cantadas. ${ }^{21}$

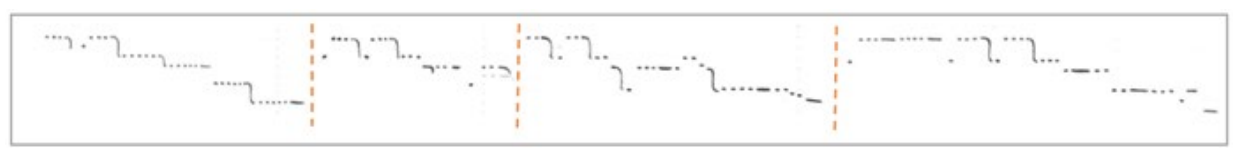

Figura I: Versión 2013, fragmento

20 Si bien la práctica de la improvisación puede inferirse con observar las diferencias sustanciales entre versiones, confirmé este dato en comunicaciones personales con tres miembros de la comunidad mocoví que estuvieron presentes desde el primer momento en que Salteño comenzó a cantar públicamente Ñetonqataiqén (Dora Salteño, Salvador Salteño y Cesar Coria).

21 Las líneas de puntos que grafican las articulaciones entre las frases fueron colocadas de acuerdo con mi percepción auditiva. La tendencia que observé, y que devino en criterio para seccionarlas, fue, por un lado, la finalización de las frases en la altura más grave con una duración larga, y por otro lado, el inicio de algunas frases con la repetición de la altura más aguda. 


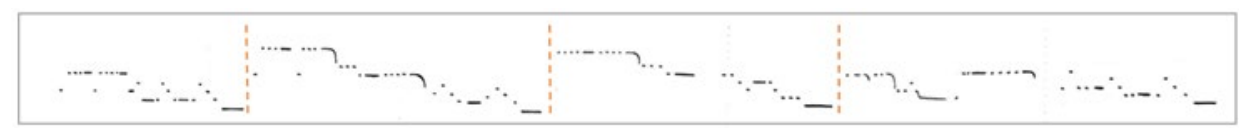

Figura 2: Versión 20I4, completa

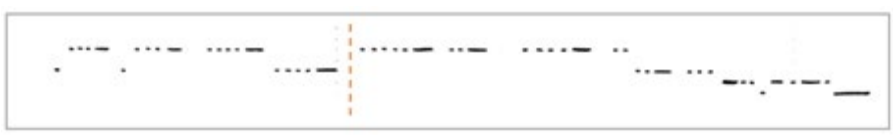

Figura 3: Versión 2015, sección de canto silábico completa

Pese a tales diferencias se puede percibir un perfil melódico predominantemente en terrazas con «escalones» descendentes conformados por nota repetida. ${ }^{22}$

El ritmo que prevaleció en el canto puede asociarse a la palabra central de la canción: ñetonqataiqén (figura 4). Sin embargo, el vínculo estrecho entre células rítmicas y las palabras utilizadas en el canto silábico (que no siempre tienen ni la misma cantidad de sílabas ni la misma acentuación que la palabra ñetonqataiqén) generaron variaciones en las células rítmicas. ${ }^{23}$ La letra, al ser improvisada, también fue modificada en cada performance.

22 De acuerdo con mi percepción, las melodías de las tres versiones parecieran estar estructuradas en base a un centro tonal y a un modo mayor. Coadyuva a tal percepción la insistencia sobre algunas alturas cruciales para la apreciación de ambos aspectos (tónica y modo): repetición de la 5 ta y la $8 \mathrm{va}$, detenciones sobre la 3ra mayor, 6ta mayor y detenciones sobre el 2do grado que desciende a la fundamental en finales de frase. En el caso de la segunda versión (2014), la guitarra presenta una secuencia armónica que alterna entre I y V7 de La M y la melodía del canto se estructura en base a la función de los acordes: las frases descienden hasta el 2do grado cuando la armonía es V7 y hasta la tónica cuando es I. Además, finaliza con dos arpegios rasgueados $(\mathrm{V} 7-\mathrm{I})$, uno por cada pulso, que parecieran reafirmar la condición tonal de esta versión. Sin embargo, aún no he tenido la oportunidad de dilucidar el repertorio de posibilidades y parámetros musicales que operan en el paradigma estético de Salteño como para afirmar que mi percepción (de un centro tonal y de un modo mayor) también es compartida por él.

23 Las acentuaciones son principalmente agógicas: se perciben puntos jerarquizados en la melodía cuando las alturas presentan mayor duración. En los gráficos precedentes, correspondientes a los perfiles melódicos, las duraciones están representadas con la longitud del trazo. 


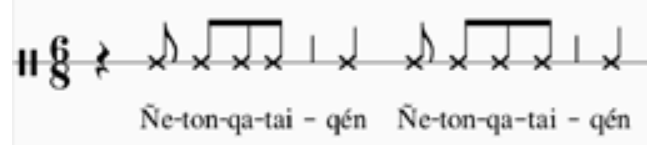

Figura 4: Patrón rítmico principal de la voz

El tambor, por su parte, presentó un patrón rítmico correspondiente a una de las prácticas musicales y coreográficas de antaño del pueblo mocoví en la región litoraleña, el tontoyogo, ${ }^{24}$ con algunas variaciones momentáneas (figura 5). En la segunda versión, este ritmo se superpone con el rasguido de chamamé realizado por la guitarra.

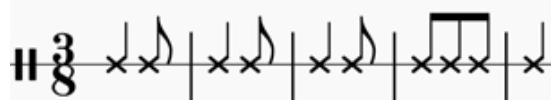

Figura 5: Patrón rítmico del tontoyogo

El violín monocorde (registrado solo en la primera versión) efectuó durante la mayor parte de la canción (a excepción de los primeros 40 segundos) un gesto característico: línea melódica que alterna entre el uso

24 El ritmo que transcribo fue tomado de uno de los registros sonoros correspondientes a la reunión del año 2014 mencionada en el segundo apartado de este artículo (Ñetonqataiqén). Según el relato de Sartor, tal ritmo fue atribuido al tontoyogo por los miembros de la comunidad Aim Mokoilek que participaron de esa grabación. Asimismo, Cesar Coria (presente en aquel momento) me confirmó este dato en una comunicación personal durante julio del año 2020. Según los datos ofrecidos por la Encuesta Nacional de Folklore de 1921, las narrativas de ancianos y ancianas mocoví relevadas por Citro y las entrevistas que vengo efectuando, el tontoyogo formaba parte de los "bailes paisanos" (Citro \& Cerletti 2006:41; Encuesta Nacional de Folklore 1921, Leg. Santa Fe, f. 52). Llama la atención la atribución de un patrón rítmico a este baile (en los registros de 2014) teniendo en cuenta que en las etnografías realizadas por Citro entre los años 2003 y 2006 fue referido como una práctica musical y coreográfica olvidada. Evidentemente, durante la última década, algunas comunidades, entre ellas la de Colonia Dolores, han estado emprendiendo procesos de memoria, revisión y reelaboración de prácticas musicales y coreográficas del pasado. El nombre del baile también puede encontrarse como toncoyogo o tonto yugo. El único registro en notación musical que pude observar sobre esta danza pertenece a la Encuesta Nacional de Folklore de 1921. Allí, el ritmo registrado, en coincidencia con el informado en 2014 , se encuentra en pie ternario. Este es otro tópico que requiere mayor detenimiento y sobre el cual pretendo indagar en un futuro trabajo. 
de nota repetida y de glissandos, y alternancia repetitiva entre «empujar» $y$ «tirar» con el arco:

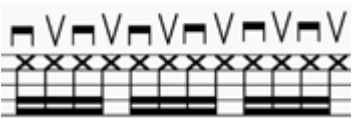

Figura 6: Gesto del violín monocorde

En cuanto al contexto de las interpretaciones, las versiones de 2013 y 2015 comparten características similares: fueron realizadas en el marco de encuentros comunitarios. En ambos eventos Salteño interactuó, por momentos, con los danzantes. ${ }^{25} \mathrm{La}$ influencia que este tipo de interacciones tuvo en la resultante sonora se evidencia sobre todo en la primera versión. En ella se puede observar, hacia al final, un incremento del tempo, un cambio en la emisión vocal, un aumento en el volumen de la voz y una elevación de la melodía que anticipa a los bailarines la conclusión del baile. Además, Salteño alternó entre usos distintos de la voz (cantado y hablado) para dirigirse a estos últimos (interacción que no existe en la segunda grabación). En ambos registros puede observarse que la participación es, principalmente, de adultos.

En síntesis, las versiones de Salteño presentaron variaciones en múltiples parámetros. Las melodías del canto y de la flauta, la instrumentación, el comportamiento rítmico, la letra, la duración de cada sección, la emisión vocal y las interacciones con los bailarines se modificaron de acuerdo con factores situacionales.

25 En la danza participan principalmente adultos (varones y mujeres), los niños aparecen en escasa cantidad en ambos registros. 


\section{$4 \cdot$ LA VERSIÓN DE SARTOR}

El proceso creativo de Sartor puede dividirse en, al menos, cuatro instancias ${ }^{26}$ de las cuales dos se caracterizaron por la comunicación, la participación colectiva y el consenso entre el músico y miembros de algunas comunidades mocovíes, entre ellos, el mismo Salteño.

La primera instancia consistió en «sintetizar», en una versión única, diferentes interpretaciones que Salteño efectuó durante comunicaciones personales con el músico. Según el relato de Sartor, tales versiones presentaban divergencias en el comportamiento melódico y rítmico teniendo unas «ritmo de chamamé» y otras «ritmo de tontoyogo». Ante esto, Sartor decidió privilegiar las segundas por considerarlas mayormente representativas del pueblo mocoví. ${ }^{27} \mathrm{El}$ trabajo resultante de esta instancia fue la musicalización de un texto en mocoví (definido por Salteño) teniendo en cuenta algunas constantes melódicas y rítmicas presentes en las interpretaciones del dirigente.

La segunda instancia, de creación colectiva, sucedió durante el $2 d o$ Encuentro con las Comunidades Aborígenes del año 2016 organizado en la localidad de San Javier. Allí, Sartor aprovechó la presencia de maestros bilingües para interpretar su propuesta musical y verificar que el texto en mocoví elaborado por Salteño sea inteligible en su nueva musicalización. Su versión fue juzgada positivamente, con lo cual continuó solicitando el asesoramiento de los maestros presentes para traducir el texto al español. Uno de sus objetivos era la inclusión de secciones que resulten comprensibles a los niños/as a los cuales iba a ser enseñada la canción. ${ }^{28}$

\footnotetext{
26 Todos los datos que brindo sobre este proceso creativo y las comunicaciones en torno al mismo me fueron relatados por Sartor en entrevistas realizadas durante el año 2020.

27 La intención de Sartor era la de basarse en «un ritmo que fuera común o que fuera parte importante de la vida de los mocovíes" (comunicación personal, junio de 2020). Según los trabajos etnográficos más importantes sobre esta sociedad, el chamamé ha formado parte de los repertorios musicales interpretados en sus celebraciones tradicionales (Citro, 2006a). Evidentemente, en las decisiones estéticas de Sartor, se ha negado la posibilidad de que músicas de procedencia criolla sean lo suficientemente representativas de la tradición cultural de los pueblos originarios.

28 No todas las traducciones obtenidas durante esa instancia se ajustaban a la métrica musical pensada por Sartor, con lo cual el texto definitivo en español fue reelaborado posteriormente por el escritor sanjavierino Hugo Ríos (conservando las ideas principales del texto en mocoví).
} 
Finalmente, las dos últimas instancias consistieron, por un lado, en la definición de la instrumentación, armonización y arreglos instrumentales, por otro lado, en su registro sonoro. Esta última dio como resultado tres grabaciones realizadas en estudio de las cuales la primera fue considerada por Sartor como "provisoria», siendo las últimas dos las «definitivas». Si bien podrían comprenderse como tres versiones diferenciadas, las notorias similitudes entre ellas evidencian, a mi entender, la intención del músico en elaborar una única versión, con lo cual las trataré aquí de tal modo, en singular.

En la nueva versión, el músico repone las instrumentaciones observadas en las versiones de Salteño, aunque sutilmente modificadas: utiliza flauta dulce en lugar de pinkuyo, bombo legüero en lugar de tambor, chaschas en vez de sonajeros de calabaza o chauchas, y voces de niños/ as en lugar de una voz masculina adulta. Algunas de estas elecciones se corresponden al orgánico del proyecto La Flauta de Paikí, el cual estaba compuesto principalmente por niños/as y flautas dulces. Asimismo, hubo una intención de mantener la configuración instrumental representativa referida en el apartado anterior (aerófono y membranófono) como también la inclusión del violín monocorde (viké moqoi, ver nota I8) que, si bien no es utilizado colectivamente en las comunidades mocoví, Sartor lo ha considerado un instrumento también representativo:

Tabla 3: Orgánico musical de todas las versiones

\begin{tabular}{|c|c|c|c|c|}
\hline Versiones & 2013 (Salteño) & 2014 (Salteño) & 2015 (Salteño) & 2016 (Sartor) \\
\hline & $\begin{array}{l}\text { Voz (masculina, } \\
\text { adulta) }\end{array}$ & $\begin{array}{l}\text { Voz (masculina, } \\
\text { adulta) }\end{array}$ & Voz (masculina, adulta) & $\begin{array}{l}\text { Voces (mixtas, } \\
\text { infantiles) }\end{array}$ \\
\hline & Pinkuyo & Pinkuyo & & Flauta dulce \\
\hline & Violín monocorde & & & Violín monocorde \\
\hline & & Guitarra & & Guitarras \\
\hline & Tambor & Tambor & & Bombo legüero \\
\hline & & & $\begin{array}{l}\text { Sonajeros de calabaza/ } \\
\text { Chauchas }\end{array}$ & Chaschas \\
\hline
\end{tabular}


En el aspecto melódico, logra cierta similitud con las versiones de Salteño al reponer el perfil melódico por terrazas con «escalones» descendentes conformados por nota repetida y al estructurar la melodía sobre las alturas de un acorde perfecto mayor. Sin embargo, en esta nueva versión, tanto el perfil melódico como las alturas se repiten de modo idéntico en cada una de las frases sin presentar variaciones (como lo hacían las versiones de Salteño) con lo cual todas frases presentan la misma duración:

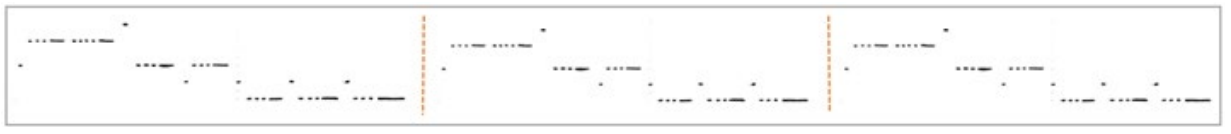

Figura 7: Nueva versión, fragmento

$\mathrm{Al}$ igual que en las versiones analizadas de Salteño, la célula rítmica que estructura al canto es la asociada a la palabra ñetonqataiqén (figura 4), pero aquí Sartor la emplea sin ningún tipo de modificaciones. El ritmo «base» (ejecutado por el bombo y la guitarra) es el de tontoyogo (figura 5) y se percibe un notorio cuidado por sostener la regularidad del pulso. Esto último puede observarse en las duraciones de cada sección correspondientes a las tres grabaciones efectuadas:

Tabla 4: Duraciones por sección

\begin{tabular}{|c|c|c|c|c|c|c|c|c|c|}
\hline & \multicolumn{9}{|c|}{ Secciones/duración } \\
\hline & Voc-instr. & Instr. & \multicolumn{4}{|c|}{ Voc-instr. } & Instr. & \multicolumn{2}{|c|}{ Vocal-instr. } \\
\hline \multicolumn{10}{|l|}{ Grabación 1} \\
\hline & - & $21 "$ & $14 "$ & $14 "$ & $14 "$ & $14 "$ & $14 "$ & $14 "$ & $28 "$ \\
\hline \multicolumn{10}{|l|}{ Grabación 2} \\
\hline & - & $21 "$ & $14 "$ & $14 "$ & $14 "$ & $14 "$ & $14 "$ & $14 "$ & $28 "$ \\
\hline \multicolumn{10}{|l|}{ Grabación 3} \\
\hline & $21 "$ & $21 "$ & $14 "$ & $14 "$ & $14 "$ & $14 "$ & $14 "$ & $14 "$ & $28^{\prime \prime}$ \\
\hline
\end{tabular}


En cuanto al violín monocorde, a diferencia de la versión de 2013 (que alternaba entre el uso de nota repetida y de glissandos), aquí el gesto transcripto en la figura 6 se efectúa mayormente sobre una misma altura, la tónica (Sol).

El texto de la canción quedó estructurado por secciones en idioma mocoví y español. ${ }^{29}$

Netonqataekén, nowiró nagaá,

qobó, amokoit, ñetonqataekén,

ñetonqataeén, ñetonqataekén, ñetonqataekén.

Qaia doqolek, nokikirokén,

souenanqoó, ñetonqataekén,

ñetonqataeén, ñetonqataekén, ñetonqataekén.

Alegrémonos, llegamos aquí,

con nuestro pueblo, todos a cantar,

alegrémonos, alegrémonos, alegrémonos!

La fiesta empezó, con flauta y tambor,

acerquémonos, hermano blanco,

alegrémonos, alegrémonos, alegrémonos!

Cheqoqomniík, nokikirokén,

Qomagoe qaiá, secaiapaglék,

ñacaipí, alipí, ialiripií.

Saoqotaekén, ñaátikolek,

ka kotaiolek, ñetonqataekén,

ñetonqataeén, ñetonqataekén,

alegrémonos, alegrémonos,

29 Transcribo el texto exactamente como me lo compartió Sartor. 
ñetonqataekén, ñetonqataeqén,

alegrémonos, alegrémonos,

ñetonqataekén, ñetonqataeqén, ñetonqataekén.

\section{$5 \cdot$ UnA CANCIÓN «DESPLAZADA»}

Luego de haber cotejado las versiones quisiera enunciar una serie de «desplazamientos» que observo entre la nueva versión y las anteriores. Considero necesario aclarar que con el término «desplazamiento» no pretendo abordar una propuesta conceptual, sino esbozar simplemente una metáfora que ayude a graficar mentalmente el carácter «móvil», «trashumante» de la canción y de los elementos musicales y contextuales que la constituyen. Los «desplazamientos» a los que hago referencia son tres (que si bien considero relevantes no son los únicos ni se presentan siguiendo un orden jerárquico).

El primero de ellos consistió en desplazar a Netonqataiqén desde un paradigma estético que tolera un amplio grado de variación en relación con factores situacionales hacia otro en el cual la canción adquiere una serie de parámetros «fijos». Esto se presenta en dos dimensiones. Por un lado, en el desplazamiento desde el dominio de lo «oral» (que admite ciertas flexibilizaciones en el discurso) al dominio de lo «escrito" (de carácter prescriptivo). En la versión de Sartor las decisiones estéticas estuvieron orientadas a elaborar una "versión única» factible de ser enseñada en las escuelas. De este modo y, en contraste con las interpretaciones de Salteño, donde primaba la improvisación, quedaron estipulados elementos como: el número de frases melódicas y su extensión, el repertorio de alturas, el esquema formal, la secuencia armónica, el ritmo, la cantidad de palabras, las palabras mismas y su ordenamiento. Por otro lado, la segunda dimensión se corresponde al comportamiento rítmico y melódico. A diferencia de las versiones de Salteño, la de Sartor presenta frases periódicas estructuradas sobre un mismo patrón rítmico y melódico que se reitera sin alteraciones. 
El segundo desplazamiento está asociado al protagonismo dentro de la práctica musical. Con la intervención de Sartor, «Ñetonqataiqén» se traslada desde una práctica musical que concibe como protagonista (y líder) del canto a una figura masculina y adulta (característica mayormente afín a la tradición mocoví de antaño) hacia otra que pone en el centro de la performance a un grupo de niños/as, modificando el número de participantes y el rango etario.

Finalmente, el tercer desplazamiento atañe a las condiciones de circulación. Originalmente, «Ñetonqataiqén» era escuchada en los encuentros comunales e intercomunales mediante su ejecución en vivo. Luego de la intervención de Sartor, la canción comenzó a estar disponible en formato digital y, por tanto, a ser portable y replicable con lo cual tomó múltiples derroteros.

\section{$6 \cdot \tilde{N}$ ETONQATAIQÉN EN LA LUCHA}

Planteado este panorama, quiero retrotraerme a uno de los interrogantes propuestos al inicio para lograr vincular lo tratado hasta aquí con el proceso, más amplio, de las luchas y acciones por la visibilización de la sociedad mocoví en la provincia de Santa Fe. Me pregunto, entonces, ¿qué posibilidades de acción, dentro de este movimiento social, habilitan los «desplazamientos» analizados en "Ñetonqataiqén»? ${ }^{30}$

En primer lugar, las «fijaciones» adquiridas en el primer desplazamiento parecieran incrementar la factibilidad de la canción para ser interpretada por diversos grupos de personas. El desplazamiento de lo «oral» a lo «escrito» genera prescripciones principalmente en el diseño melódico, el repertorio de alturas, el comportamiento rítmico y el texto que hacen viable su transcripción e/o incorporación al repertorio de uno o

30 Esta interrogante está inspirada en el concepto de musical affordance utilizado por Tia De Nora para referir a aquellas acciones que habilita, permite o invita a realizar un objeto musical. En su trabajo «La música en acción: constitución del género en la escena concertista de Viena, 1790-1810" el término aparece traducido como "habilitación musical». En una rigurosa nota al pie por parte de la traductora se menciona que el término affordance tiene otras traducciones posibles como, por ejemplo, «invitabilidad", "provisión" o "potencialidad" (De Nora, 2012:188). 
más intérpretes musicales (como ya lo realizó, por ejemplo, el coro polifónico Santa Cecilia de la ciudad de San Javier). ${ }^{31}$

Para el caso particular del proyecto La Flauta de Paiki, tales «fijaciones» parecieran haber coadyuvado a la realización de algunas tareas prácticas del quehacer musical. Por un lado, facilitaron la enseñanza y el aprendizaje de la canción (la memorización se vio favorecida al estar estructurada sobre una misma frase melódica y rítmica). ${ }^{32}$ Por otro lado, garantizaron cierta cohesión en la interpretación conjunta, lo cual no fue un aspecto menor teniendo en cuenta que La Flauta de Paikí estaba conformada por grupos de niños/as pertenecientes a cuatro escuelas rurales que no tenían un espacio de ensayo compartido. Las características musicales de la nueva versión permitieron un ensamble sin mayores inconvenientes y, en consecuencia, que dicha canción, con texto y autor mocoví, ${ }^{33}$ se ubique dentro del repertorio del proyecto junto a otras canciones de autores reconocidos.

El segundo desplazamiento, por su parte, pareciera apelar desde lo sonoro a un rango etario particular como también acentuar semióticamente (con el incremento en el número de cantantes) las ideas de «unión» $\mathrm{y}$ «fraternidad» que se translucen en la letra («llegamos aquí con nuestro pueblo, todos a cantar», «acerquémonos, hermano blanco»). Tal protagonismo otorgado a nińos/as y a la práctica musical colectiva muestra su potencial si se trae a colación el surgimiento de otros proyectos musicales gestados durante el proceso de «reemergencia étnica» mocoví, además de La Flauta de Paikí. Me refiero al grupo de canto colectivo Com Caiá de la comunidad mocoví de Recreo, ${ }^{34}$ al coro de niños/as de la comunidad de Helvecia ${ }^{35}$ y al proyecto de cancionero en lengua mocoví llevado

31 Puede escucharse en: https://www.youtube.com/watch?v=U9t5ZYjCdIU

32 Al respecto, durante nuestras conversaciones Sartor me relató una situación en la cual un grupo de niños/ as perteneciente a una de las escuelas involucradas juzgó a la nueva versión como "fácil». Asimismo, Dora Salteño me ha referido a la «rapidez» con la cual los/as niños/as de las escuelas aprendieron la canción.

33 A pesar de su intervención, Sartor ubica a Salteño como el autor.

34 Localidad santafesina perteneciente al departamento La Capital. Es dirigido por Miguel Ángel Bochini y su último material discográfico puede encontrarse en Spotify.

35 Helvecia es una localidad santafesina ubicada en el departamento Garay. Fue dirigido por Silvia Lanche. 
a cabo por Sergio Roszezuk ${ }^{36}$ en la localidad de Villa Ángela (provincia de Chaco). Todos ellos comparten una explícita apuesta al protagonismo de nińos/as no solo en las prácticas musicales, sino dentro del proceso general de visibilización. ${ }^{37} \mathrm{Si}$ bien tales proyectos no han funcionado sincrónicamente en todo momento y no todos continúan en actividad actualmente, tuvieron algunos puntos de contacto como, por ejemplo, la convergencia en encuentros intercomunales o la interpretación, por parte de alguna de las agrupaciones, de canciones creadas por otra de ellas. ${ }^{38}$ En un contexto como este, el segundo desplazamiento, que pone en el centro de la acción a los/as niños/as y ensalza la práctica colectiva, pareciera habilitar la participación de «Ñetonqataiqén» en dicha escena a la vez que incrementa a esta última.

Finalmente, las habilitaciones del tercer desplazamiento (cambio en las condiciones de escucha y circulación) pueden observarse en dos dimensiones. Por un lado, en los usos de la canción efectuados por actores externos a las comunidades, y por otro, en los usos realizados al interior de las mismas. Para referir a la primera, creo relevante mencionar la inclusión de la nueva versión de "Ñetonqataiqén» dentro de los recursos pedagógicos propuestos por la Asociación del Magisterio de Santa Fe (AMSAFE) en su página web a los fines de ser utilizada en las Escuelas Interculturales Bilingües de la provincia. Aquí, las nuevas condiciones de circulación (su formato digital, portable y replicable) no solo habili-

36 A través del trabajo colectivo entre Roszezuk y docentes bilingües de la ciudad de Villa Ángela se buscó generar un cancionero que trate temas vinculados a la infancia y a la juventud. Muchas de las canciones compuestas en el marco de este proyecto se encuentran disponibles en YouTube.

37 A este conjunto podría sumarse la notable participación de niños/as y adolescentes en las prácticas musicales y coreográficas efectuadas al interior de los cultos de las iglesias evangélicas presentes en numerosas comunidades mocoví de la provincia de Santa Fe. Se trata de instituciones con un rol relevante en los procesos de reagrupamiento y visibilización de los pueblos mocoví en dicha región. El estudio de su escena musical y su relación con tales fenómenos sociales amerita una indagación exhaustiva.

38 Por ejemplo: la convergencia del grupo Com Caiá y algunos/as niños/as de La Flauta de Paikí en el IV Encuentro con las Comunidades Aborígenes del año 2018 en San Javier; la inclusión de una canción compuesta por el grupo Com Caiá en el repertorio del coro de Helvecia; o bien, la intención de M. A. Bochini de incluir a "Ñetonqataiqén" en el repertorio de la agrupación que dirige (comunicación personal en agosto del 2020). Asimismo, en uno de los videos disponibles en YouTube correspondiente a una de las canciones del proyecto de Rozcezúk, se explicitaba en un comentario la intención de interpretarla en el Encuentro de Comunidades Mocovíes organizado en Melincué (Santa Fe) durante el año 2014 (actualmente los comentarios se encuentran desactivados). 
taron lo más «esperable» (ponerla a disposición de un circuito de actores más amplio, los cuales pueden vincularse estéticamente con esta tanto en la escena escolar como en la doméstica, grupal e individualmente), sino que facilitaron su adopción y difusión por parte de un organismo educativo que la inscribió en una esfera institucional a nivel provincial, la vinculó a otras producciones (musicales, visuales, literarias) y le asignó una posible metodología de uso. ${ }^{39}$ En esta línea podría reconocerse el accionar de otro desplazamiento, no mencionado en el apartado anterior, en relación con la inteligibilidad del texto. La coexistencia de ambos idiomas (mocoví y español) no solo favorecería la comprensión del texto por parte de un mayor número de personas (lo cual podría incidir en la vinculación afectiva con el mismo), sino que la vuelve una canción particularmente útil para la enseñanza intercultural bilingüe.

Para referir a la segunda dimensión, quisiera relatar brevemente lo que me parecieron dos ejemplos potentes de las habilitaciones del tercer desplazamiento. El primero de ellos tuvo lugar en la localidad de Colonia Dolores a partir del año 20I6. Según el relato de Dora Salteńo, ese mismo año Alfredo Salteño presentó problemas de salud que lo imposibilitaron de interpretar «Ñetonqataiqén» durante los encuentros. Ante esto, se garantizó la continuidad del evento musical y coreográfico luego del encendido del «fuego sagrado» con la utilización de la grabación realizada por Sartor. El segundo ejemplo, refiere al uso de la nueva versión de «Ñetonqataiqén» en abril del año 2020 durante el vi Encuentro con las Comunidades Aborígenes organizado por AMSAFe. Debido al contexto sanitario se realizó de modo virtual y consistió en una seguidilla de videos breves grabados por diferentes comunidades o personas individuales que fueron transmitidos en vivo en el día y la hora acordados. ${ }^{40}$ En uno de ellos, el correspondiente a la comunidad mocoví Kami iava de la provincia de Santa Fe, se observaba la realización de un ritual cir-

39 Si bien la canción se encuentra disponible dentro de los recursos pedagógicos ofrecidos por AMSAFE para trabajar en las Escuelas Interculturales Bilingües, no he realizado hasta el momento una indagación sobre los usos efectivos de la misma por parte de docentes y alumnos/as ni de sus impactos en tales instituciones. La canción se encuentra disponible en https://amsafe.org.ar/no-dejamos-de-enseniar/interculturalidad/

40 Video disponible en el siguiente link: https://www.youtube.com/watch?v=fMljQIRogDU\&t=56s 
cular alrededor del «fuego sagrado» para el cual decidieron incorporar como banda sonora la nueva versión de «Ñetonqataiqén». ${ }^{41}$

En ambos casos, la versión de Sartor, en sus nuevas condiciones de circulación, facilitó la posibilidad de reponer, tanto presencial como virtualmente, un momento performático que se había visto altamente perjudicado. Paradójicamente, el «Ñetonqataiqén» que parecía alejarse del ritual del fuego para ganar terreno en los ensayos, las escuelas y en los escenarios, retornó al ámbito del cual surgió posibilitando un nuevo modo de hacer performance, presentando alternativas de acción ante momentos desfavorables.

\section{$7 \cdot$ Palabras finales}

Si bien es vasto lo que resta analizar sobre los recorridos de esta canción, sobre sus condiciones de recepción (colectivas e individuales), sobre la dimensión estética presente en las interacciones entre grupos originarios y no originarios, e incluso sobre los «costos» que estas últimas podrían implicar (lo cual constituye un asunto para un futuro análisis) considero que hasta aquí fue posible echar un poco de luz sobre los interrogantes planteados al inicio de este escrito.

«Ñetonqataiqén» se presenta como un ejemplo concreto de interacción entre actores, externos e internos a las comunidades, en el marco de un proceso de reivindicación étnica. A pesar de ser un «micro-ejemplo", indagar en sus usos y transformaciones pareciera haber resultado fructífero para dilucidar algunas de las direcciones hacia las cuales apunta este movimiento social. En este sentido, creo que podrían reconocerse al menos dos dimensiones simultáneas en los procesos de visibilización del pueblo mocoví. Por un lado, aquellas actividades que promueven una visibilización «hacia dentro», introspectiva, que busca fortalecer al colectivo y resignificar la propia historia (recuperación de prácticas rituales pasadas, transmisión del idioma, creación de nuevas expresiones

41 Ante mi consulta, Patricia Hernández (actual secretaria adjunta de la Junta Directiva Provincial de AMSAFE) me confirmó que la utilización de esa versión fue solicitada por la comunidad Kami iava. 
representativas, apuesta e incentivo a la participación de las generaciones jóvenes), y por otro lado, aquellas acciones que promueven una visibilización «hacia fuera", que aspira a la concreción de un posible Estado plurinacional (incremento de la representación y la participación efectiva dentro de las esferas institucionales provistas por el Estado y la academia; «apertura», comunicación y negociación con actores y entidades no indígenas; promoción de espacios de diálogo y de acción junto a otros pueblos originarios). Ambas dimensiones, por supuesto, están fuertemente imbricadas en tanto las acciones y las conquistas en una de ellas resultan de insumo para la otra.

En un contexto como este, los «desplazamientos» realizados en «Ñetonqataiqén» parecieran haber habilitado (y continuar habilitando) otros márgenes de acción, otras performances posibles que coadyuvan en distintos niveles (provinciales, intercomunales, intracomunales e individuales) a «las visibilizaciones» del pueblo mocoví.

A modo de cierre, quisiera invitar a comprender tales «desplazamientos» no solo como acciones acontecidas en el pasado, como meras consecuencias de la intervención de Sartor, sino como parte de un proceso activo, actual, que pareciera involucrar actores múltiples a la vez que los trasciende. Más que una canción «desplazada» «Ñetonqataiqén» está «en desplazamiento». En este sentido, espero haber habilitado otras vías posibles para la creación de Salteño, haberla hecho «desplazar» también por aquí, por las páginas de este escrito, por la constelación de trabajos que dialogan en este dossier, por las ideas, las escuchas y las miradas de los lectores interesados.

\section{REFERENCIAS BIBLIOGRÁFICAS}

BARTOLOMÉ, Miguel (2006). La etnogénesis. Viejos actores y nuevos roles en el escenario cultural y político, en Procesos interculturales. Antropología política del pluralismo cultural en América Latina, México: Siglo XXI.

Citro, Silvia (2006a). La fiesta del 30 de agosto entre los mocovíes de Santa Fe, Universidad de Buenos Aires: Editorial FFYL.

CITRO, SILVIA (2006b). Tácticas de invisibilización y estrategias de resistencia de 
los mocoví santafesinos en el contexto postcolonial, Indiana, 23, 139-170.

CITRO, SILVIA Y CERLETTI, ADRIANA (2006). Integración, creatividad y resistencia cultural en las prácticas musicales mocoví, Resonancias, 19, 37-56.

CITRO, SILVIA Y TORRES AGÜERO, SOLEDAD (2015). Las músicas amerindias del Chaco argentino entre la hibridación y la exotización, Journal de la société des américanistes, 101(101-1 et 2), 203-230.

CITRO, SILVIA, MENNELLI, YANINA Y TORRES AGÜERO, SOLEDAD (2017).

Cantando al patrimonio...: las expresiones indígenas, entre discursos

globales y creatividades locales. Antipoda. Revista de Antropología y

Arqueología 29: 175-197.

DOI: HTTPS://DX.DOI.ORG/I0.7440/ANTIPODA29.20I7.08 [CONSULTADO EL I $6 / 7 / 2021]$

Dalla-Corte caballero, gabriela (2012). Mocovies, franciscanos

y colonos de la zona chaqueña de Santa Fe. 1850-2011: el

liderazgo de la mocovi Dora Salteño en Colonia Dolores. Rosario: Prohistoria Ediciones; TEIAA, Universidad de Barcelona.

DE NORA, TIA (2012). La música en acción: constitución del género en la escena concertista de Viena, 1790-1810. En C. BENZECRY (comp.) Hacia una nueva sociología cultural, Universidad Nacional de Quiles Editorial, 187-213.

DEL RÍo, PAULA (Ed.) (2013). El patrimonio cultural de la comunidad Mocoví Aim Mokoilek Colonia Dolores, Rosario: UNR Editora.

ENCUESTA NACIONAL DE FOLKLORE DE I 92 I. BUENOS AIRES. INSTITUTO NACIONAL DE ANTROPOLOGÍA Y PENSAMIENTO LATINOAMERICANO.

GILBERT, ABEL y LIUT, MARTín (comps.) (2019). Las mil y una vida de las canciones, Buenos Aires: Gourmet Musical.

HADDAD, ROSARIO (2018). El "rap originario" como práctica cultural entre jóvenes y niños qom, Cuadernos del Instituto Nacional de Antropología y Pensamiento Latinoamericano, 27(1), 17-31.

HADDAD, ROSARIO (2020). "Cantar y tocar lo propio": Sobre los procesos de reafirmación y legitimación identitaria en un barrio indígena qom. En GONZÁLEZ MORENO, Liliana et al. (eds.) (2020). Del archivo a la playlist: historias, nostalgias, tecnologías. Actas del XII Congreso de la IASPM-AL, Mendoza, IASPM-AL. PAUCKE, FLORIAN (2010). Hacia allá y para acá. Santa Fe: Espacio Santafesino Ediciones.

RUíz, IRMA (1985). Los instrumentos musicales de los indígenas del Chaco central, Revista del Instituto de Investigación Musicológica "Carlos Vega" (6), 35-78.

RUíz, IRMA (2003). De lo real a lo posible: la problemática de la gestación del movimiento pan-indígena argentino y su «músicas», Revista Argentina de Musicología (3-4), 15-44.

40 | Netonqataiqén, una canción «en desplazamiento» [VALENTín MansiLla] 